LA-UR-00-6114

Approved for public release; distribution is unlimited.

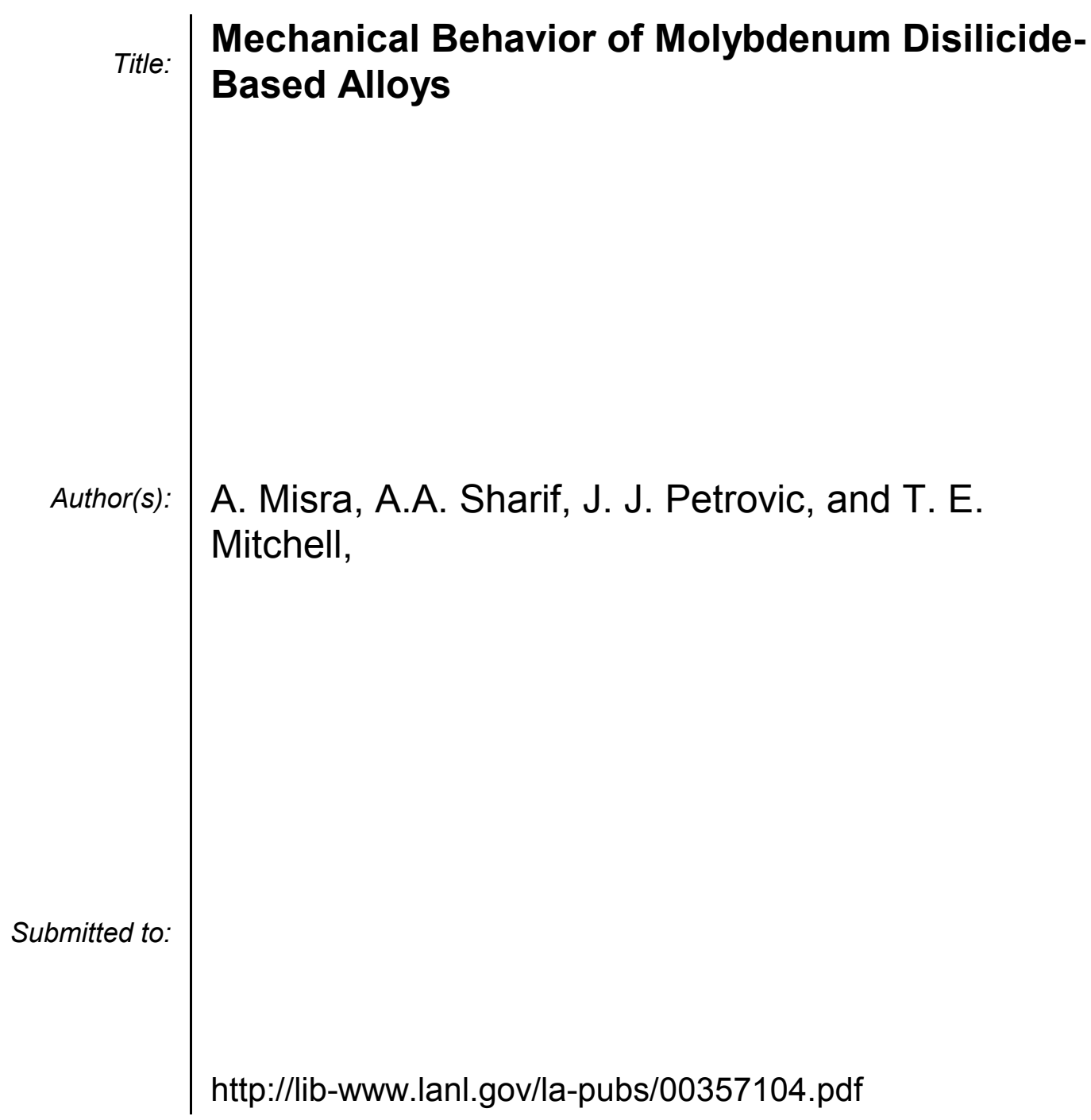

Los Alamos National Laboratory, an affirmative action/equal opportunity employer, is operated by the University of California for the U.S. Department of Energy under contract W-7405-ENG-36. By acceptance of this article, the publisher recognizes that the U.S. Government retains a nonexclusive, royaltyfree license to publish or reproduce the published form of this contribution, or to allow others to do so, for U.S. Government purposes. Los Alamos National Laboratory requests that the publisher identify this article as work performed under the auspices of the U.S. Department of Energy. Los Alamos National Laboratory strongly supports academic freedom and a researcher's right to publish; as an institution, however, the Laboratory does not endorse the viewpoint of a publication or guarantee its technical correctness. 


\section{Mechanical Behavior of Molybdenum Disilicide-Based Alloys}

A. Misra, A.A. Sharif ${ }^{1}$, J. J. Petrovic, and T. E. Mitchell, MST Division, Los Alamos National Laboratory, Los Alamos, NM 87545

${ }^{1}$ University of Michigan, Department of Engineering Science, Flint, MI 48502

\section{ABSTRACT}

We have investigated the mechanical behavior of the following single-phase polycrystalline alloys with the $\mathrm{MoSi}_{2}$ body-center tetragonal structure: $\mathrm{MoSi}_{2}$ alloyed with 2.5 at. $\% \mathrm{Re}, \mathrm{MoSi}_{2}$ alloyed with 2 at.\% $\mathrm{Al}, \mathrm{MoSi}_{2}$ alloyed with 1 at.\% $\mathrm{Nb}$, and $\mathrm{MoSi}_{2}$ alloyed with 1 at.\% Re and 2 at.\% Al. Several anomalies in the mechanical behavior of alloyed materials were observed. For example, (i) addition of only $\sim 2.5$ at. \% Re results in an order of magnitude increase in compressive strength at $1600{ }^{\circ} \mathrm{C}$, (ii) additions of $\mathrm{Nb}$ and $\mathrm{Al}$ cause solution softening at nearambient temperatures, and (iii) quaternary $\mathrm{MoSi}_{2}-\mathrm{Re}-\mathrm{Al}$ alloys show strengthening at elevated temperatures and reduction in flow stress with enhanced plasticity at near-ambient temperatures in compression. The mechanisms of anomalous solution hardening and softening are discussed.

\section{INTRODUCTION}

Significant increases in the operating temperatures of high-temperature structural components will only be possible if superalloys are replaced with higher melting temperature intermetallic or ceramic materials [1-2]. Refractory metal silicides such as $\mathrm{MoSi}_{2}, \mathrm{Mo}_{5} \mathrm{SiB}_{2}, \mathrm{Nb}_{5} \mathrm{Si}_{3}$, etc. typically have melting temperatures in excess of $2000{ }^{\circ} \mathrm{C}$ and are potential materials for use at temperatures exceeding the melting point of Ni-base superalloys [1-3]. In addition to the low room temperature fracture toughness, the strengths of monolithic silicides at temperatures above $\sim 1400{ }^{\circ} \mathrm{C}$ are typically very low. Silicides in the composite form, either with ceramic reinforcements (e.g., $\left.\mathrm{MoSi}_{2}-\mathrm{SiC}\right)$ or eutectics $\left(\mathrm{MoSi}_{2}-\mathrm{Mo}_{5} \mathrm{Si}_{3}\right)$, often show enhanced high temperature strengths but the room temperature fracture toughness is still very low [4]. Ductile metallic reinforcements such as $\mathrm{Nb}$ react with the disilicide matrix to form other silicides and have limited practical use for long-term high temperature applications, although improvements in toughness have been demonstrated in these composites [5]. This approach, however, may be promising for Si-poor silicides, as shown in systems such as Nb-Nb $5 \mathrm{Si}_{3}, \mathrm{Mo}_{2}-\mathrm{Mo}_{5} \mathrm{SiB}_{2}$, etc. [6].

Due to the complex crystal structures and presumably limited deformation capability of these compounds, little work has been done on studying how alloying in the single-phase region influences the deformation behavior. Recent studies on single crystal $\mathrm{MoSi}_{2}$ have shown compressive plasticity even at temperatures below ambient $[7,8]$. Furthermore, first principles calculations have predicted that solutes such as $\mathrm{Al}, \mathrm{Nb}, \mathrm{Mg}$ and $\mathrm{V}$ may enhance the ductility of $\mathrm{MoSi}_{2}$ [9]. In the present investigation, we have chosen $\mathrm{MoSi}_{2}$ as a model material (Fig. 1) to study selected substitutional alloying effects that are anomalous as compared to the classical theories for metals.

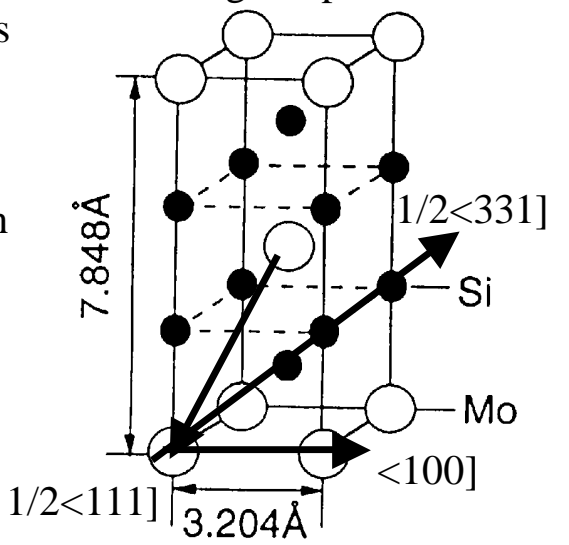

Fig.1 Body-centered tetragonal unit cell of $\mathrm{MoSi}_{2}$; slip vectors are shown by arrows. 


\section{EXPERIMENTAL PROCEDURES}

Pure $\mathrm{MoSi}_{2}$, ternary $(\mathrm{Mo}, \mathrm{Re}) \mathrm{Si}_{2},(\mathrm{Mo}, \mathrm{Nb}) \mathrm{Si}_{2}, \mathrm{Mo}(\mathrm{Si}, \mathrm{Al})_{2}$ and quaternary $(\mathrm{Mo}, \mathrm{Re})(\mathrm{Al}, \mathrm{Si})_{2}$ alloys were prepared by arc-melting high-purity elements in an argon atmosphere. The starting melt compositions were $\mathrm{MoSi}_{\mathrm{x}}$, with $\mathrm{x}=2.01$ to account for the $\mathrm{Si}$ loss during melting. The buttons were turned over and remelted 4 times for homogeneity. Alloying levels were in the 1-2 at.\% range. Compression testing was performed on $2 \times 2 \times 4 \mathrm{~mm}^{3}$ samples, polished to $0.05 \mu \mathrm{m}$ finish, in air using an Instron 1125 machine at an initial strain rate of $\sim 1 \times 10^{-4} / \mathrm{s}$. Transmission electron microscopy (TEM) was performed on a Philips CM30 microscope operating at $300 \mathrm{kV}$.

\section{RESULTS}

All materials tested were polycrystalline with large grain sizes on the order of $100 \mu \mathrm{m}$. Compression testing revealed three unusual phenomena in these alloys that are described below:

\section{Anomalous Hardening}

Alloying with Re in the $1-2 \%$ level resulted in large increases in the high temperature $(\mathrm{T})$ yield strength of $\mathrm{MoSi}_{2}$ (Fig. 2). No tests were conducted at $\mathrm{T}>$ $1600{ }^{\circ} \mathrm{C}$. At $\mathrm{T}<900{ }^{\circ} \mathrm{C}$, fracture before yield was typically observed and data for $\mathrm{MoSi}_{2}$ are estimated from tests on single crystals [7,8]. Fig. 2 is a loglinear plot, where linear fits to the data are consistent

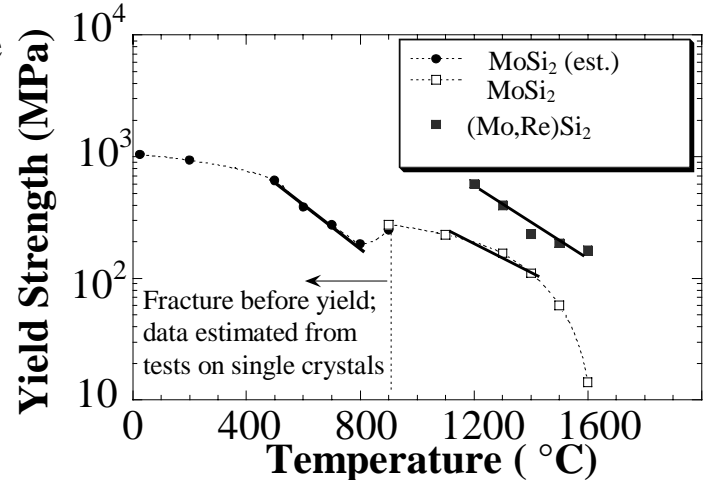

Fig. 2 Effect of 2.5 at.\% Re on the high T strength of polycrystalline $\mathrm{MoSi}_{2}$. Data at $\mathrm{T}$ $<900{ }^{\circ} \mathrm{C}$ are estimated (est.) from single crystal tests $[7,8]$. with a Peierls-stress controlled behavior [10]. Note that the strength of $\mathrm{MoSi}_{2}$ drops significantly at $\mathrm{T}>1400{ }^{\circ} \mathrm{C}$, while the Re-alloys show better strength retention. Even at $1600{ }^{\circ} \mathrm{C}$, the addition of only 2.5 at.\% Re resulted in an order of magnitude increase in high temperature strength.

\section{Solution Softening}

Fig. 2 shows that Re is a potent hardener in $\mathrm{MoSi}_{2}$, but the Re-alloys exhibit no plasticity in compression at $\mathrm{T}<1000{ }^{\circ} \mathrm{C}$. Fig. 3 shows examples of alloying effects that enhance the room temperature compressive plasticity of $\mathrm{MoSi}_{2}$. At $\mathrm{T} \leq 900^{\circ} \mathrm{C}$, the yield strength of polycrystalline $\mathrm{MoSi}_{2}$ is estimated from critical resolved shear stresses for $\{110)<111]$ slip at $\mathrm{T}>500{ }^{\circ} \mathrm{C}$, and $\left.\{011)<100\right]$ at $\mathrm{T}<500{ }^{\circ} \mathrm{C}$, measured on single crystals. Note that both $\mathrm{Nb}$ (1 at.\%) and $\mathrm{Al}$ (2 at.\%) alloys are deformable at room $\mathrm{T}$ at strength levels significantly lower than the estimated yield strength of $\mathrm{MoSi}_{2}$ at room T. At T < $800{ }^{\circ} \mathrm{C}$, the temperature dependence of flow stress of $\mathrm{MoSi}_{2}$ is also lowered by $\mathrm{Nb}$ and $\mathrm{Al}$ additions.

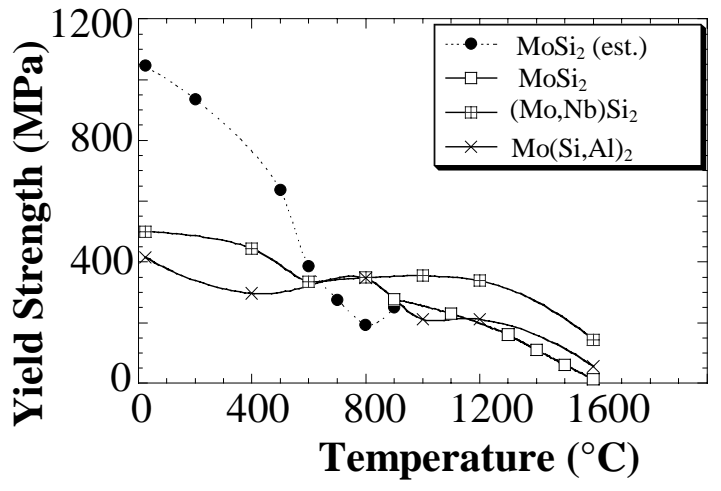

Fig. 3 Effects of 1 at.\% $\mathrm{Nb}$ and 2 at.\% $\mathrm{Al}$ alloying, respectively, on the yield strength of polycrystalline $\mathrm{MoSi}_{2}$. The alloys exhibit compressive plasticity at room temperature. 
High T Hardening and Low T Softening

Fig. 4 shows two examples where alloying additions have both increased the high $\mathrm{T}$ strength and reduced the low $\mathrm{T}$ yield strength enough to cause compressive plasticity at room $\mathrm{T}$. This behavior is best exhibited by the quaternary $(\mathrm{Mo}, \mathrm{Re})(\mathrm{Si}, \mathrm{Al})_{2}$ alloys that contained only 1 at.\% Re and 2 at.\% Al. In other words, these alloys combine the beneficial effects of Re (high $\mathrm{T}$ hardening) and $\mathrm{Al}$ (low $\mathrm{T}$ softening) alloying shown in Fig. 2 and 3. Similar effect is seen with $\mathrm{Nb}$ additions (Fig. 3 and 4 ), where only 1 at.\% $\mathrm{Nb}$ lowers the minimum $\mathrm{T}$ at which compressive plasticity is observed from

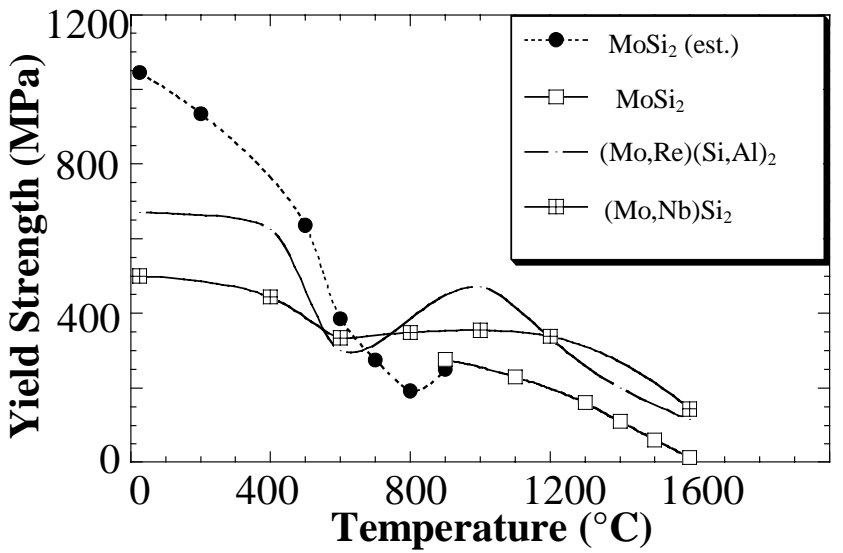

Fig. 4 Quaternary $(\mathrm{Mo}, \mathrm{Re})(\mathrm{Si}, \mathrm{Al})_{2}$ alloys with $\sim 1$ at.\% Re and 2 at.\% $\mathrm{Al}$ are stronger than $\mathrm{MoSi}_{2}$ at high $\mathrm{T}$ and softer at near-ambient $\mathrm{T}$. Ternary $\mathrm{Nb}$ containing alloys exhibit similar behavior. $\sim 900{ }^{\circ} \mathrm{C}$ to ambient, and resulted in high T hardening. The Al-containing ternary alloys (Fig. 3), however, have insignificant effect on high $\mathrm{T}$ strength.

\section{Dislocation Substructures}

In unalloyed $\mathrm{MoSi}_{2}$, dislocation substructures were similar to those observed in pure metals deformed at elevated temperatures [11]. Regular cell structures and sub-grains were observed at deformation $\mathrm{T}>1300{ }^{\circ} \mathrm{C}$ consistent with climb controlled deformation, i.e., glide is easy and climb of dislocations over substructure obstacles is the rate controlling step. The Re-containing alloys show "viscous glide" controlled substructures, i.e., lots of free dislocations and tangles of the <100] and $1 / 2<111>$ type, with little tendency to form cell structures even at $1600{ }^{\circ} \mathrm{C}$. Furthermore, weak beam imaging of the $1 / 2<111\rangle$ dislocations indicated that Re alloying increases the stacking fault energy [11].

In the ternary $(\mathrm{Mo}, \mathrm{Nb}) \mathrm{Si}_{2}, \mathrm{Mo}(\mathrm{Si}, \mathrm{Al})_{2}$ and the quaternary $(\mathrm{Mo}, \mathrm{Re})(\mathrm{Al}, \mathrm{Si})_{2}$ alloys, the dislocation substructures at temperatures where solution softening is observed (i.e., $\mathrm{T}<\sim 600^{\circ} \mathrm{C}$ ) consisted primarily of $1 / 2<111>$ dislocations, with some $<100>$ dislocations as shown in Fig. 5 . The preferred line direction of the $1 / 2<111>$ dislocations appeared to be $60^{\circ}$ from screw, consistent with similar observations on unalloyed $\mathrm{MoSi}_{2}[7,8]$. While polycrystalline $\mathrm{MoSi}_{2}$ could not be deformed at low temperatures in compression, studies of dislocations under hardness indents in polycrystalline $\mathrm{MoSi}_{2}$ have revealed primarily <100> type dislocations at these temperatures [12]. This suggests that alloying elements such as $\mathrm{Nb}$ and $\mathrm{Al}$ that cause solution softening at low temperatures may promote $1 / 2<111\rangle$ slip in $\mathrm{MoSi}_{2}$. A similar inference was made through an analysis of slip traces around room temperature hardness indents on single crystalline $\mathrm{Mo}\left(\mathrm{Si}, \mathrm{Al}_{2}\right)_{2}[13]$, and more recently, through compression testing on single crystals [14]. Another important effect revealed in weak beam imaging of $1 / 2<111>$ dislocations in $\mathrm{Nb}$ alloyed materials, Fig. 5, (and also, Al-alloyed materials not shown here) is that partial spacing is increased, i.e., stacking fault energy is lowered, consistent with other studies [14,15].

At intermediate temperatures $\left(\sim 800-1000^{\circ} \mathrm{C}\right)$, when the flow stress increases anomalously with increasing temperatures, still predominantly $1 / 2<111>$ dislocations are observed in the $\mathrm{Nb}$ and $\mathrm{Al}$-alloyed $\mathrm{MoSi}_{2}$. Note that at these temperatures, solution softening is not observed. Most 
of the $1 / 2<111>$ dislocations on $\{110>$ planes are in the form of "bundles" at these temperatures, i.e., groups of several dislocations closely spaced, separated by relatively dislocation free regions. These dislocations showed a stronger tendency as compared to $400{ }^{\circ} \mathrm{C}$ to be straight and mostly be along the $60^{\circ}$ orientation. The anomalous increase in the yield strength with increasing temperature has been interpreted as a Portevin-Le Chatelier effect in unalloyed $\mathrm{MoSi}_{2}$, presumably caused by interstitial impurities, even though impurity levels as low as 40 wtppm were reported in floatzone crystals studied by Ito et al.

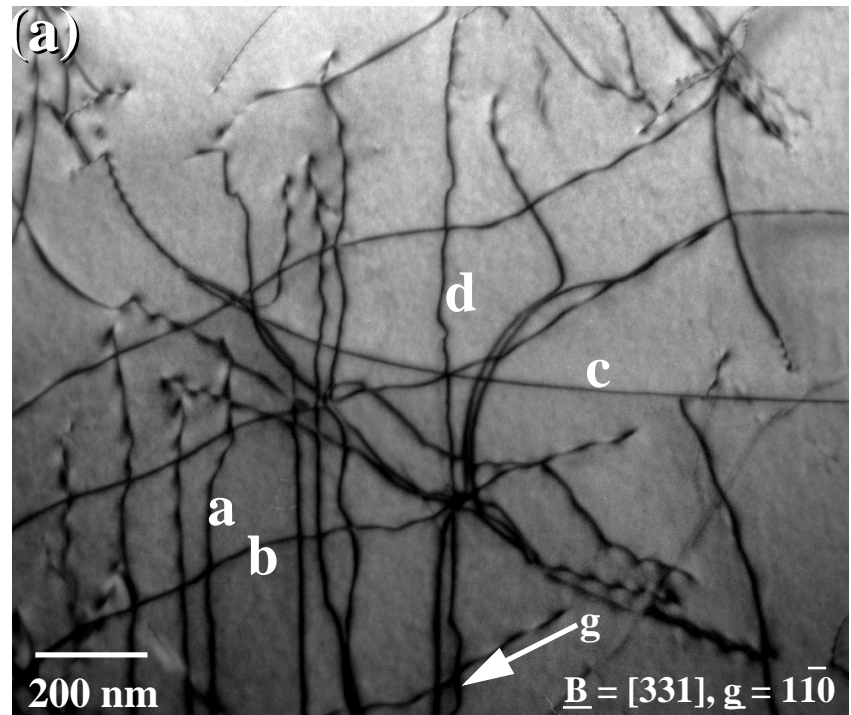

(b)

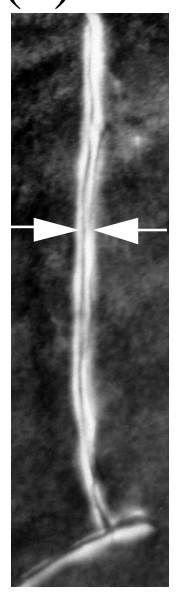

Fig. 5 (a) Bright field and (b) weak beam TEM micrographs showing the dislocation substructures in a $\mathrm{MoSi}_{2}-1$ at.\% $\mathrm{Nb}$ alloy compressed $\sim 0.5 \%$ at $400{ }^{\circ} \mathrm{C}$. The labels a and $\mathrm{d}$ correspond to $<100$ ], and $\mathrm{b}$ and $\mathrm{c}$ correspond to $1 / 2<111>$ type dislocations respectively. The weak beam image shows that the $1 / 2<111>$ dislocations are dissociated into $1 / 4<111>$ partials, with lower fault energy than unalloyed $\mathrm{MoSi}_{2}$. [7]. An alternate view is that the $60^{\circ}$ non-screw dislocations lie along the <110] directions which are common to several low-index intersecting planes such as \{110), (001) and \{331). Hence, the possibility of a non-planar dislocation core at these temperatures with segments on planes where the critical resolved shear stress for glide is very high cannot be ruled out. Our present work shows that anomalous yielding is also observed in alloyed $\mathrm{MoSi}_{2}$. Needless to add, the mechanisms of anomalous yielding in $\mathrm{MoSi}_{2}$ need to be studied in more detail including first principles and atomistic simulations of dislocations, as shown in a recent study by Mitchell et al. [16].

At elevated temperatures $\left(>1200{ }^{\circ} \mathrm{C}\right)$, the $\mathrm{Nb}$ alloyed materials are harder than $\mathrm{MoSi}_{2}$ and dislocation substructures (Fig. 6) show predominantly <100] type dislocations and dipole loops that may be pinched-off gliding $<100>$ dislocations. Several short <110> dislocation segments are also seen formed as a reaction product between [100] and [010] dislocations. Since this work is on polycrystals, the critical resolved shear stresses for $\langle 111\rangle$ and $<100]$ dislocations could not be determined as a function of temperature. Also, more statistics is needed to quantitatively assess the relative amounts of $\langle 111\rangle$ and $<100]$ slip at elevated temperatures. From Fig. 6, it does, however, appear that $\langle 111\rangle$ slip is not as favored as it is at lower temperatures compared to <100] slip.

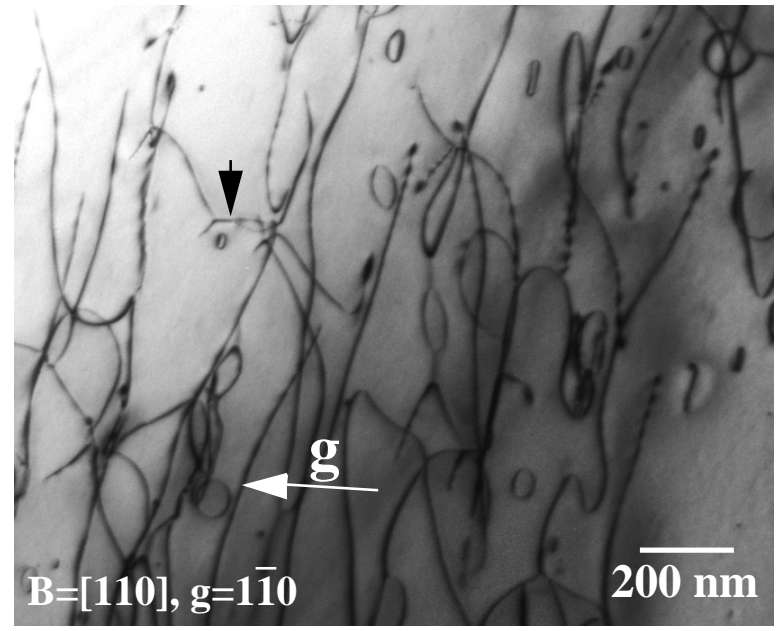

Fig. 6 Bright field TEM micrograph from a $\mathrm{MoSi}_{2}-1$ at. $\% \mathrm{Nb}$ alloy deformed $\sim 1 \%$ at $1200^{\circ} \mathrm{C}$. All dislocations in this micrograph have a $<100]$ type Burgers vector. Reactions between [100] and [010] produce [110] dislocations (e.g., marked with an arrow), and dipole loops, that may have been "pinched-off" from glide dislocations are also seen. 


\section{DISCUSSION}

The rapid solution hardening of $\mathrm{MoSi}_{2}$ by $\mathrm{Re}$ at elevated temperatures is anomalous and may not be explained within the framework of the classical solution hardening theories based on atomic size and modulus misfits. Since rhenium "disilicide" has a Si-deficient stoichiometry corresponding to $\mathrm{ReSi}_{1.75}$ [17], a $\mathrm{Si}$ vacancy may form with every four Re atoms added. The pairing of $\mathrm{Re}$ substitutionals with $\mathrm{Si}$ constitutional vacancies will result in point defect complexes with elliptical strain fields and hence, strong interaction with both edge and screw dislocations. The fact that hardening is observed even at $1600{ }^{\circ} \mathrm{C}$ indicates that these defect complexes are very stable. A dislocation model for this rapid hardening has been presented elsewhere [11], and we only discuss the solution softening here.

With regard to solution softening in $\mathrm{MoSi}_{2}$, we note the following features: (i) softening is caused by elements such as $\mathrm{Nb}, \mathrm{Al}$, Ta, etc. that change the structure of $\mathrm{MoSi}_{2}$ from bodycentered tetragonal $\left(\mathrm{C} 11_{\mathrm{b}}\right)$ to hexagonal, (ii) softening occurs only at low concentrations (typically $<2-3$ at.\%) in the single-phase $\mathrm{C} 11_{b}$ structure, i.e., at higher concentrations of $\mathrm{Nb}$ or Al when the structure changes to hexagonal, the normal hardening behavior is observed, (iii) softening occurs only at low temperatures $\left(<\sim 600{ }^{\circ} \mathrm{C}\right)$, and (iv) all solutes that soften $\mathrm{MoSi}_{2}$ lower the stacking fault energy, as inferred from the $1 / 4<111>$ partial spacing. Furthermore, Harada et al [18] have shown that elements such as $\mathrm{Zr}$ with a strong affinity for interstitial impurities did not result in any significant softening. This led Harada et al to conclude that the scavenging of interstitial solutes by $\mathrm{Al}$ (or, $\mathrm{Nb}$ ) may not be the dominant mechanism for solution softening in $\mathrm{MoSi}_{2}$. The more likely mechanism is the lowering of the Peierls stress and/or easier double kink nucleation in the presence of solutes. Waghmare et al. [9] have shown, through firstprinciples calculations, that elements such as $\mathrm{Nb}, \mathrm{Al}, \mathrm{Mg}$, and $\mathrm{V}$ change the generalized stacking fault energy $(\gamma)$-surface of dislocations in $\mathrm{MoSi}_{2}$. Since Peierls stress is given directly by the maximum gradient of the $\gamma$-surface, the net effect of solutes such as $\mathrm{Nb}$ and $\mathrm{Al}$ was predicted to be a lowering of the Peierls barrier at low homologous temperatures. Experimentally, we observed that $\mathrm{Nb}$ and $\mathrm{Al}$ lowered the stacking fault energy, and the increased $1 / 4<111>$ partial spacing may result in increased mobility of these partials, consistent with the lower Peierls barrier predicted by Waghmare et al [9]. The reason why these solutes segregate to the $1 / 2<111>$ dislocation may be related to the higher solubility of these solutes in the hexagonal structure of $\mathrm{MoSi}_{2}$. The difference in the tetragonal and hexagonal structures of $\mathrm{MoSi}_{2}$ is that former has $\mathrm{ABAB}$ stacking while the latter has $\mathrm{ABCABC}$ stacking of $\{110)$ planes. The stacking sequence in the fault that separates the two $1 / 4<111>$ partials in the otherwise tetragonal $\mathrm{MoSi}_{2}$ is also ABCABC. Thus, solutes that stabilize the hexagonal structure are likely to segregate to the fault. We further speculate that at elevated temperatures, changes in the core structure (e.g., climbassisted) and/or solute mobility may reduce the effect of solute on the $\gamma$-surface and the Peierls stress.

\section{SUMMARY}

The anomalous effects of substitutional alloying, at $<2$ at.\% level, on the mechanical behavior of polycrystalline $\mathrm{MoSi}_{2}$ are summarized as follows:

(i) Rapid hardening by Re at elevated temperatures: an order of magnitude increase in compressive strength was observed at $1600{ }^{\circ} \mathrm{C}$, and is interpreted as due to strong interactions of both screw and edge dislocations with Re substitutional-Si vacancy point defect complexes. 
(ii) Solution Softening at temperatures $<\sim 600{ }^{\circ} \mathrm{C}$ : alloying with either $\mathrm{Nb}$ or $\mathrm{Al}$ caused a decrease in yield strength at these temperatures. The $\mathrm{Nb}$ or Al-alloyed $\mathrm{MoSi}_{2}$ exhibited compressive plasticity at room temperature, while the unalloyed $\mathrm{MoSi}_{2}$ fractured before yield at $\mathrm{T}<\sim 900{ }^{\circ} \mathrm{C}$. We hypothesize that these solutes, through a lowering of the stacking fault energy, are able to lower the Peierls barrier at low temperatures.

(iii) Low Temperature Softening and High Temperature Hardening: observed in ternary $(\mathrm{Mo}, \mathrm{Nb}) \mathrm{Si}_{2}$ and quaternary $(\mathrm{Mo}, \mathrm{Re})(\mathrm{Si}, \mathrm{Al})_{2}$ alloys. These results, particularly the quaternary alloys, indicate a non-linear addition of the effects of different solutes, e.g., Al effect dominates at low temperatures and Re effect at high temperatures.

\section{ACKNOWLEDGEMENT}

This research was funded by Department of Energy, Office of Basic Energy Sciences. We acknowledge discussions with M. Baskes, S.P. Chen and R.G. Hoagland.

\section{REFERENCES}

1. J.J. Petrovic and A.K. Vasudevan, Mat.Sci.Eng.A, 261, 1-5 (1999).

2. T.E. Mitchell, R.G. Castro, J.J. Petrovic, S.A. Maloy, O. Unal and M.M. Chadwick, Mat.Sci.Eng.A, 155, 241 (1992).

3. R. Gibala, A. K. Ghosh, D. C. Van Aken, D. J. Srolovitz, A. Basu, H. Chang, D. P. Mason and W. Yang, Mater. Sci. Eng.A, 155, 147 (1992).

4. K. Ito, T. Yano, T. Nakamoto, M. Moriwaki, H. Inui and M. Yamaguchi, Prog. Mat. Sci., 42, 193 (1997).

5. K.T.V. Rao, W.O. Soboyejo and R.O. Ritchie, Met.Trans.A, 23, 2249-2257 (1992).

6. J.H. Schneibel, C.T. Liu, D.S. Easton and C.A. Carmichael, Mat.Sci.Eng.A, 261, 78 (1999).

7. K. Ito, H. Inui, Y. Shirai and M. Yamaguchi, Phil. Mag. A, 72, p 1075 (1995).

8. S.A. Maloy, T.E. Mitchell and A.H. Heuer, Acta Metall.Mater., 43, 657 (1995).

9. U.V. Waghmare, V. Bulatov, E.Kaxiras and M.S. Duesbery, Mat.Sci.Eng.A, 261, 147 (1999).

10. T.E. Mitchell, P. Peralta and J.P. Hirth, Acta Mat., 47, 3687 (1999).

11. A. Misra, A.A. Sharif, J.J. Petrovic and T.E. Mitchell, Acta Mat.,48, 925-932 (2000).

12. S.A. Maloy, A.H. Heuer, J.J. Lewandowski and T.E. Mitchell, Acta Metall. Mater., 40, 3159 (1992).

13. P. Peralta, S.A. Maloy, F. Chu, J.J. Petrovic and T.E. Mitchell, Scripta Mat., 37,1599 (1997).

14. H. Inui, et al., this symposium proceedings.

15. D.J. Evans, F.J. Scheltens, J.B. Woodhouse and H.L. Fraser, Phil. Mag. A, 75, 17 (1997).

16. T. E. Mitchell, M. I. Baskes, S. P. Chen, J. P. Hirth and R. G. Hoagland, Phil. Mag.A, in press.

17. A. Misra, F. Chu and T.E. Mitchell, Phil. Mag.A, 79, 1411 (1999).

18. Y. Harada, Y. Murata and M. Morinaga, Intermetallics, 6, 529-535 (1998). 